\title{
Socioeconomic, Demographic, and Environmental Associated with Stunting among Children under Five Years old in Ethiopia: Evidence from Ethiopian Demographic and Health Survey, 2016
}

Getnet Bogale Begashaw ( $\sim$ getnetbogale145@gmail.com )

Wollo University

Yordanos Berihun Yohannes

Addis Ababa University - Selale Campus

\section{Research}

Keywords: Multi-Level Logistic Regression Model; Malnutrition; Stunting; Underweight; Wasting

Posted Date: March 10th, 2020

DOI: https://doi.org/10.21203/rs.3.rs-16521/v1

License: (9) (1) This work is licensed under a Creative Commons Attribution 4.0 International License. Read Full License 


\section{Abstract}

Background: Stunting is one of the most serious but least addressed health problems in the world. Adequate nutrition is essential for children's health and development. Globally it is estimated that, directly or indirectly, for at least $35 \%$ of deaths in children less than five years of age. Under nutrition is also a major cause of disability preventing children who survive from reaching their full development potential. Methods: Statistical models that can treat the categorical response variable like binary logistic regression model will be employed. Beside this study will include Socio -economic and demographic factors; Sex and age of child, age of mother, Educational status, occupation, health status, religion, sex of household head, number of children under five years, Household income, family size, land ownership and time of cultivation, income source of household, wealth index as independent variables. Empty model, random intercept and fixed slope with random coefficient are the method of analyzing the dataset. Result: The prevalence of stunting among children ages under five years old were about $49.3 \%$. Months of breastfeeding, educational level, and wealth index, currently pregnant and child food nutrient are significantly associated with stunting presence. The odds of stunting status of child from women who are pregnant is more likely to be stunted 4.157 compared to non-pregnant women controlling for other variables in the model and random effects at level two. Women who feed nutrient food to their child are 1.239 more likely to be stunted $(\mathrm{OR}=1.239)$ than women who didn't feed nutrient food controlling for other variables in the model and random effects at level two. Conclusions : Age of child, breast feeding, sex, pregnant status, and food nutrient were found to be significantly associated with stunting in multilevel modeling of random coefficient model. Finally random coefficient model best fit the EDHS 2016 dataset. Therefore, interventions that focus on breast feeding, period of next pregnancy, food nutrient taken by children are required for improving child stunting in Ethiopia.

\section{Background}

Globally, an estimated 171 million children are stunted, including 167 million children in low- and middle-income countries (Black et al. 2013). Globally, the percentage of children under age 5 who are stunted has decreased, from $40 \%$ in 1990 to $28 \%$ in 2010 , with an anticipated further drop to $22 \%$ (142 million) by 2020 [1]. In Africa, however, prevalence of stunting among children under age 5 was $36 \%$ compared with $27 \%$ in Asia, estimated in 2011. It is projected that by 2020 , Asia and Africa will have almost similar numbers of stunted children (68 million and 60 million, respectively). These levels are much higher than the number of children stunted in Latin America, at 7 million in 2010 [2].

The higher prevalence of child stunting in Africa and Asia is a public health problem that has often gone unrecognized. Child stunting reflects a failure to receive adequate nutrition over a long period of time and may be affected by intrauterine growth retardation, poor feeding practices, and frequent exposure to infections [3]. When stunting spans generations, it results in grave consequences that include poor quality of life, morbidity, and mortality [4,5]. The 2014 Demographic and Health Surveys (DHS surveys) for Kenya and Cambodia showed that the prevalence of stunting among children under age 5 was $22 \%$ and $25 \%$ respectively. The prevalence of stunting in children under age 5 in Kenya and Cambodia was higher, at 32\% and 26\% respectively [6].

Researchers have found that poverty, poor health and nutrition, and social factors are associated with risks to child growth. These factors have prevented over 200 million children in developing countries from attaining their full potential [7]. In developing countries, where mostly women are denied a voice in household decisions, they 
are most likely to be undernourished themselves and less likely to have access to resources that can be directed toward children's nutrition [8].

In Ethiopia $40 \%$ of children under age five were stunted and $18 \%$ of children were severely stunted with regional variation such as in South Nation Nationality Peoples 44.3\%, Afar 49.2\%, Tigray 44.4\%, Amhara National Region State $42.4 \%$ children under five were stunted [9]. Stunting is affected by many factors such as: poverty, low parental education, lack of sanitation, low food intake, poor feeding practices, inadequate breastfeeding, repeated infections, family size and birth interval [5].

Stunting remains one of the most common causes of morbidity and mortality among children throughout the world. It has been responsible, directly or indirectly, for $60 \%$ of the 10.9 million deaths annually among children under five. Over two-thirds of these deaths, which are often associated with inappropriate feeding practices, occur during the first year of life. Malnutrition is one of the leading causes of morbidity and mortality in children under the age of five in developing countries. Ethiopia being one of these countries malnutrition is an important public health problem. There is no information available on the stated problem. This study is, therefore, aimed at assessing associated factors of stunting children under five years old.

The general objective of this study is to empirically investigate the major factors that are associated with stunting among children below five years old in Ethiopia. The specific objectives of the study is to determine the prevalence of stunting among the children aged below five years, to determine the socio-demographic and economic characteristics of households of children aged below five years and to estimate the within-regional and between-regional level of difference for the incidence of stunting among under five-children in Ethiopia.

\section{Methods}

(see Methods in the Supplementary Files)

\section{Results}

\subsection{Descriptive Statistics}

This research utilized the national wide Ethiopia Demographic and Health Survey (EDHS) 2016 collected data on the stunting of children. The analysis presented in the study is based on 11654 under-five children with complete weight-for-age anthropometric index as indicator of a children's stunting and health status among other indices, since it is an excellent overall indicator of a population's stunting and health status. Table 2: below, shows that the percentage of the severity status of child's stunting

As presented in Table 2, the prevalence of stunting found was at $48.74 \%$ were female, where males were $49.62 \%$. It shows that $49.82 \%$ of urban children were stunted, $48.54 \%$ rural of children were stunted and $46.89 \%$ of children were stunted their family no education.51.67\% of children were stunted their family were primary education, $65.28 \%$ of children were stunted their family education were secondary and $75.51 \%$ of children were stunted where their family were higher education.

As presented in Table 2, the prevalence of stunting found was $48.85 \%$ of children were stunted where their toilet was unsafe and $54.68 \%$ of children were stunted where their toilet was safe. $40.17 \%$ of children were stunted 
where poorest and $69.90 \%$ of children were stunted where richest.

Table 2 shows $46.78 \%$ of children were stunted whether currently pregnant or not $68.30 \%$ of children were stunted where they were currently pregnant. And $52 \%$ of children were stunted where they were not used a soup. $47.26 \%$ of children were stunted that they used a soup and $49.28 \%$ of children were stunted that they were not found nutrients and $46.05 \%$ of children were stunted that they were found nutrients.

Figure1: shows that the Predicted Probability of under five children stunting by predictors vs Region. The Maximum predicted log-odds range is considered as regionally varied variables thus variable duration of breast feeding is regionally varied variables and have high random effects on under-five children stunting compare to the other variables. This variable is used in the random slope model.

\subsection{Results of Multilevel Logistic Regression Analysis}

In the multilevel analysis, a two-level structure is used with regions as the second-level units and under five children as the first level units. This is basically the analysis of region wise variation of stunting among underfive children. Children were nested in regions with a total of 5732 children included in this study.

\subsubsection{Multilevel Logistic Regression Model Comparison}

The Maximum predicted log-odds range is considered as regionally varied variables thus variable age and stunting are regionally varied variables and have high random effects on under-five children stunting morbidity compare to the other variables. These variables are used in the random slope model.

The deviance-based chi-square value for the empty model shown in the above Table 3: is the difference in log likelihoods between an empty model of single level logistic regression and empty model of multilevel logistic regression, which is to be compared with the critical value from the chi-squared distribution with 1 degree of freedom. The significance of this test implies that an empty model with random intercept is better than an empty model without random intercept. The significant deviance-based chi-square value and smallest AIC for random intercept model indicates that the random intercept and fixed slope model is a better fit as compared to the empty model. The deviance-based chi-square test of random effects for random coefficient model is not statistically significant and has larger AIC. This implies that as compared to the model with random intercept and fixed slope model, the random coefficients model is not a better fit. Thus, in the above Table 3: shows that among multilevel logistic regression models, the random intercept and fixed slope model fits significantly better than the other multilevel logistic regression models.

\subsubsection{Results of Empty Multilevel Logistic Regression Model}

The variance of the random factor is significant which indicates that there is regional variation in experiencing stunting among under-five children (Table 4). The intercept $\beta_{O}=-1.18546$ is interpreted as the odds of stunting in an average region. That is the intercept informs us that the average probability of incidence of stunting everywhere in Ethiopia is $\exp (-1.18546) /[1+\exp (-1.18546)]=0.234$. The intra-region correlation in intercept only model is 0.049 which is significant at $5 \%$ level of significance. This result implied that $4.9 \%$ of the variation in the incidence of stunting can be explained by grouping the under-five children in regions (higher level units). 
The remaining $(100-4.9 \%=95.1 \%$ of the variation of incidence of stunting is explained within region-lower level units.

The variance of the regional level residuals errors, symbolized by is estimated to be 0.140688 . This parameter estimate is larger than the corresponding standard errors and calculation of the Z-test shows that it is significant at $p<0$. 025. The significance of this residual term indicates that there are regional differences in the women unemployment status in Ethiopia.

The deviance-based Chi-square (deviance $=521.19)$ indicated in table below is the difference in deviance between an empty model without random effect (deviance $=15,764.71$ ) and an empty model with random effect (deviance $=15,243.52$ ). This value is compared to chi-square distribution with 1 degree of freedom. The significant of it $\left(X^{2}=521.19\right.$, P-value $\left.<0.0001\right)$ implies that an empty model with random intercept is better than an empty model without random intercept. The deviance reported in the above Table is a measure of model misfit; when we add explanatory variables to the model, the deviance is expected to go down.

\subsubsection{Results of Random Intercept and Fixed Slope Logistic Regression Model}

The random intercept and fixed slope logistic regression model is a multilevel model which has random intercept and fixed coefficient of predictors. As can be seen from Table 5: the analysis of multilevel logistic regression revealed that incidence of stunting in under-five children varied among regions. The value of is the estimated variance of the intercept in random intercept and fixed coefficients model. The result displayed that the regionwise difference in the incidence of childhood stunting was statistically significant. In addition, age of child, maternal working status, duration of breastfeeding, stunting, wasting, and underweight were also found to be significant determinants of incidence of stunting among the regions.

The deviance-based Chi-square (deviance $=928.61)$ taken from single logistic regression analysis is the difference in deviance between the empty model with random intercept (deviance $=15,243.52$ ) and fixed slope model with random intercept (deviance $=14,314.91)$. The significant of it $\left(X^{2}=928.61, D F=15, P\right.$-value $<$ 0.0001 ) implies that fixed slope model with random intercept model is better than empty model with random intercept. Therefore, this model is a better fit as compared to the empty model with random intercept.

Moreover, the AIC and BIC value for fixed slope model with random intercept $(A I C=14,751.85$, and $B I C=14,762.01)$ are less than those for the empty model with random intercept $(\mathrm{AIC}=15,247.52$ and $\mathrm{BIC}=$ $15,248.31)$. This indicates that fixed slope model with random intercept is a better fit as compared to the empty model with random intercept model.

\subsubsection{Results of Random Coefficient Multilevel Logistic Regression Model}

Table 6: reveals the effect of the intercept on region $\mathrm{j}$ is estimated to be $-1.4765(0.3124)+U_{0 j}$ and their variance 0.024 (Standard error 0.070). The intercept variance of 0.024 (Standard error 0.070) is interpreted as the between-region variance when all other variables are held constant (i.e. equal to zero). Their mean is -1.4765 (standard error 0. 3124) and their variance is 0.024 (standard error 0.070). The between-region variance of slope of Breast feeding status is estimated to be 0.004 (standard error 0.002). Likewise individual region slopes of Breast feeding status vary about with a variance 0.004 (standard error 0.002 ). The negative covariance estimate 
of -0.001 (standard error 0.004) between intercept and slopes of Breast feeding status, suggest that regions with a high intercept (above-average) tends to have a flatter-than-average slope.

The quantities AIC and BIC can be used to make an overall comparison of this more complicated model with the random intercept model with fixed slope model. We see that from Table 6: the value of fit statistics for random coefficient model (AIC $=14720.79$ and $B I C=14731.35)$ is less than random intercept model (AIC=14,751.85 and $\mathrm{BIC}=14,762.01$. This indicates that the random coefficient model is a better fit as compared to the random intercept and fixed effect model.

The odds of stunting of child's from mothers who have still breast feeding were 0.601 (OR=0.601) times higher than the odds of stunting of child's from mothers who never breasted controlling other variables in the model and random effects at level two. Women who live in rural households are 0.647 more likely to be stunted $(O R=0.647)$ than women who reside in urban households controlling for other variables in the model and random effects at level two. The odds of stunting status of child from women who are pregnant is more likely to be stunted 4.157 compared to non-pregnant women controlling for other variables in the model and random effects at level two. Women who feed nutrient food to their child are 1.239 more likely to be stunted $(\mathrm{OR}=1.239)$ than women who didn't feed nutrient food controlling for other variables in the model and random effects at level two.

\subsection{Discussion}

This study analysed the Ethiopian Demographic and Health Survey 2016 dataset, exploring the effect of underlying socioeconomic, demographic, and cultural factors on under-five mortalities in Ethiopia. Under-five children whose mothers had work were $27.8 \%$ more likely to experience stunting than under-five children whose mothers had not work. These findings contradict those found in Egypt where stunting was significantly higher among children having mothers not working. This might have the implication that mothers working status affect length of breastfeeding (yilak M. 2014).

The study revealed that incidence of stunting was significantly associated with durations of breastfeeding. Under-five children who had ever been breast fed but not currently were $44.8 \%$ less likely to experience stunting as compared to under-five children who were never breasted. Under-five children who are still breastfeeding were $36.4 \%$ less likely to experience stunting as compared to under-five children who never breast fed. This present findings is in agreement with a study done in Ghana which found that infants that were either fully breastfed or mixed-fed (fed both breast milk and other foods or liquids) had a lower incidence of stunting than non-breastfed infants [5]. This finding also had confirmed with a study done in Bangladesh which showed than infants who were partially or not breastfed had a high risk of stunting death than exclusively breastfed infants [7]. Not breastfeeding resulted in high exposure of stunting morbidity in comparison to exclusive breastfeeding among infants 0-5 months of age (RR: 10.52) [17] which is also consistent with our study. This might be due to the fact that breast feeding provides vitamins and nutrients that help children develop important antibodies that reduce stunting disease.

This study found that incidence of stunting was significantly associated with nutritional status of under-five children. The prevalence of stunting was higher in stunting under-five children. The odds of having stunting in chronic malnutrition under-five children were $22.6 \%$ higher as compared to under-five children who had no 
chronic malnutrition. This finding is supported by a study done in Zimbabwe and Bangladesh that showed severely stunted children were more likely to have stunting than children of normal height and which had not severe malnutrition [18].

Under-five children who were wasting (acute malnutrition) were $49.2 \%$ more likely to experience stunting than under-five children who were not wasted. This present findings is in agreement with a study done in Uganda, which showed that being wasted increases the probability of occurrence of stunting by $14 \%$ compared to wellnourished counterparts. The study revealed that incidence of stunting was significantly associated with underweight. Under-five children who were underweight (have low weight-for age) were $54.8 \%$ more likely to experience stunting than children who were not underweight. This is consistent with a study in Ghana which showed that stunting was significantly higher for those children who were underweight (yilak M. 2014).

The finding in this study is the identification of variable at the regional level that explains the variation in stunting between the regions of Ethiopia. There are no studies involving multilevel modeling of stunting in Ethiopia that included variables at higher levels. The present study also identified socio-economic indicators of the region as predictors of unemployment. This is the exposure of stunting in different regions of Ethiopia. According to the final model, this level-two variable explains all of the regional-level variation in stunting found in the data.

\section{Conclusions}

The purpose of this study has been to identify demographic, socio-economic, environmental and nutrition related determinants and to assess regional variation of incidence of childhood stunting in Ethiopia. The descriptive results showed that $15.6 \%$ of under-five children have experienced stunting in the two weeks prior to the time of survey (EDHS 2016).

In multilevel logistic regression analysis, under-five children are considered as nested within the various regions in Ethiopia. As a first step in the multilevel approach, non-parametric statistical methods were applied to see if there were differences in the prevalence of stunting in under-five children among the regions. The non-parametric approach based on the chi-square test suggests that prevalence of stunting in under-five children varies among regions. Among the three multilevel logistic regressions models, the random intercept and fixed coefficients model provided the best fit for the data under consideration. It showed that the prevalence of childhood stunting was varying among regions. The significant determinants of prevalence of stunting among regions were age of child, maternal working status, duration of breast fed, stunting, wasting, and underweight.

The main objective of this study is to empirically investigate the major factors that are associated with stunting among children below five years old in Ethiopia. Using the EDHS 2016 data and examines the change in risk factors associated with stunting across the different EDHS years. Age of child, breast feeding, sex, pregnant status, and food nutrient were found to be significantly associated with stunting.

The odds of stunting of child's from mothers who have still breast feeding were $0.601(\mathrm{OR}=0.601)$ times higher than the odds of stunting of child's from mothers who never breasted controlling other variables in the model and random effects at level two. Women who live in rural households are 0.647 more likely to be stunted $(\mathrm{OR}=0.647)$ than women who reside in urban households controlling for other variables in the model and random effects at level two. The odds of stunting status of child from women who are pregnant is more likely to 
be stunted 4.157 compared to non-pregnant women controlling for other variables in the model and random effects at level two. Women who feed nutrient food to their child are 1.239 more likely to be stunted $(\mathrm{OR}=1.239)$ than women who didn't feed nutrient food controlling for other variables in the model and random effects at level two.

\section{Abbreviations}

CSA: Central Statistical Agency; DHS. Demographic Health Survey; SE: Standard Error; SNNPR: South Nations Nationalities of Peoples Region; UNICEF: United Nations International Children's Emergency Fund; WHO: World Health Organization

\section{Declarations}

Ethics approval and consent to participate:

Ethics approval for this study was not required since the data is secondary and is available in the public domain.

\section{Consent for publication:}

Not applicable

\section{Availability of data and materials:}

The datasets used and/ or analysed during the current study are available from the corresponding author on reasonable request.

\section{Competing interests:}

The authors declare that they have no competing interests.

\section{Funding:}

The authors have no support or funding to report.

\section{Authors' contributions:}

GB involved in the inception to design, analysis and interpretation and revises critically the manuscript and edit the manuscript for the final submission, YB involved from the inception to design, acquisition of data, analysis and interpretation, drafting the manuscript. Both authors read and approved the final manuscript.

\section{Author details}

${ }^{1}$ Department of Statistics, College of Natural Sciences, Wollo University, Dessie, Ethiopia

${ }^{2}$ Department of Statistics, College of Natural and Computational Sciences, Salale University, Fiche, Ethiopia

\section{Acknowledgments}


The authors are grateful to ICF macro (Calverton, USA) for providing the 2016 DHS data of Ethiopia.

\section{References}

1. de Onis M., Onyango A.W., Borghi E., Siyam A., Blössner M., Lutter C.K. et al.(2012)Worldwide implementation of the WHO Child Growth Standards. Public Health Nutrition 15, 1603-1610. [PubMed] [Google Scholar]

2. Mercede s de Onis*, Monika Blo“ssner and Elaine Borghi, Prevalence and trends of stunting among preschool children, 1990-2020, Public Health Nutrition: page 1 of 7

3. Long, L.A., and T. Mulatu. 2013. "Getting community-level training right: Important lessons from Ethiopia." Africa Health 35 (3):22-23.

4. Black RE, Allen LH, Bhutta ZA et al. for the Maternal and Child Undernutrition Group Maternal and child undernutrition: global and regional exposures and health consequences. Lancet. 2008; 371: 243-260

5. Ruksha na Shroff \& Sarah Lede rmann, Long-term outcome of chronic dialysis in children, Pediatr Nephrol (2009) 24:463-474 DOI 10.1007/s00467-007-0700-2

6. 2014. "Kenya Demographic and Health Survey." In, ed Kenya National Bureau of Statistics, Kenya Nairobi, National AIDS Control Council, Kenya Nairobi, National AIDS/STD Control Programme, Kenya Nairobi, Ministry of Public Health and Sanitation, Kenya Nairobi, Kenya Medical Research Institute, Kenya Nairobi, National Coordinating Agency for Population and Development, Kenya Nairobi, ICF Macro MEASURE DHS, Maryland Calverton, U.S.A.,, U.S. Agency for International Development (USAID), Kenya Nairobi and United Nations Population. http://www.dhsprogram.com/publications/publication-fr308-dhs-final-reports.cfm.

7. Arifeen S. Exclusive Breastfeeding Reduces Acute Respiratory Infection and Diarrhea Deaths Among Infants in Dhaka Slums, PEDIATRICS is the official journal of the American Academy of Pediatrics. 2001

8. Walker et al. 2007

9. UNICEF Global Nutrition Database, 2012, MICS, DHS and other national surveys, with additional analysis by UNICEF, 2006-2011.

10. 2014, CSA (Central Statistical Agency), Ethiopia Mini Demographic and Health Survey, Addis Ababa: CSA.

11. Central Statistical Agency (CSA) [Ethiopia] and ICF, Ethiopia Demographic and Health Survey 2016, CSA and ICF, MD, USA, 2016.

12. Measure DHS, Te DHS program: Demographic and Health Surveys. Rockville: ICF Macro, 2016, https://dhsprogram.com/data/availabledatasets.cfm.

13. Guang Guo and Hongxin Zhao, Multilevel Modeling for Binary Data, https://www.jstor.org/stable/223452

14. Li, M. Zhou, G. Sapiro, and L. Carin. On the integration of topic modeling and dictionary learning. In ICML, 2011.

15. Math J. J. M. Candel and Bjorn Winkens, Performance of Empirical Bayes Estimators of Level-2 Random Parameters in Multilevel Analysis: A Monte Carlo Study for Longitudinal Designs, Journal of Educational and Behavioral Statistics, Vol. 28, No. 2 (Summer, 2003), pp.169-194, American Educational Research Association and American Statistical Association, https://www.jstor.org/stable/3701260

16. Maxwell, D., C. Ahiadeke, C. Levin, M. Armar-Klemesu, S. Zakariah, and G. M. Lamptey. 1999. Alternative food security indicators: Revisiting the frequency and severity of 'coping strategies'. Food Policy 24 (4): 
411-424.

17. Laura M Lamberti , Christa L Fischer Walker, Adi Noiman , Cesar Victora , Robert E Black, Breastfeeding and the risk for diarrhea morbidity and mortality, . BMC Public Health 2011, 11(Suppl 3):S15

18. Edem M. A. Tette1, Eric K. Sifah and Edmund T. Nartey, Factors affecting malnutrition in children and the uptake of interventions to prevent the condition, Tette et al. BMC Pediatrics (2015) 15:189 DOI 10.1186/s12887-015-0496-3

19. Deepesh Bhati, Phazamile Kgosi, Ranganath Narayanacharya Rattihalli, Distribution of Geometrically Weighted Sum of Bernoulli Random Variables, Applied Mathematics, 2011, 2, 1382-1386,

20. Fauveau, C., Siddiqui, M., Briend, A., Silimperi, D. R., Begum, N., \& Fauveau, V. 1992. Limited impact of a targeted food supplementation programme in Bangladeshi urban slum children. Ann Trop Paediatric, 105(3)

\section{Tables}

Table 1: Variables in the Study

\begin{tabular}{|c|c|c|}
\hline No. & $\begin{array}{l}\text { Variable } \\
\text { Description }\end{array}$ & Code (If any) \\
\hline & $\begin{array}{l}\text { Breast feeding } \\
\text { status }\end{array}$ & 0=never breastfed; $\quad 1=$ inconsistent \\
\hline & Sex of child & $0=$ female; $\quad 1=$ male \\
\hline & Age of child & \begin{tabular}{|ll}
0 0->29 months; & $1-<30$ months
\end{tabular} \\
\hline & Residence of child & $1=$ rural \\
\hline & $\begin{array}{l}\text { Level of education } \\
\text { of Mother }\end{array}$ & $0=$ no education; $1=$ primary; $2=$ secondary $3=$ higher \\
\hline & Use of toilet & $0=$ unsafe; $\quad 1=$ safe \\
\hline & Pregnant status & $0=$ no; \\
\hline & $\begin{array}{l}\text { Food nutrient } \\
\text { status }\end{array}$ & $0=$ no; \\
\hline & Region & $\begin{array}{l}\text { Addis Ababa }=0 \text { (ref), Tigray }=1, \text { Afar }=2, \text { Amhara }=3, \\
\text { Oromya }=4, \text { Somali }=5 \text {, Benishangul }- \text { Gumuz }=6, \text { SNNP }=7, \\
\text { Gambella }=8, \text { Harari }=9, \text { Dire Dawa }=10\end{array}$ \\
\hline
\end{tabular}

Table 2: Descriptive Statistics of Variables 




Table 3: Multilevel Logistic Regression Model for Stunting and their Deviance Based Chi-square Test Statistics.

\begin{tabular}{|l|r|r|r|}
\hline & $\begin{array}{c}\text { Empty } \\
\text { model }\end{array}$ & $\begin{array}{c}\text { Random intercept } \\
\text { model }\end{array}$ & \multicolumn{1}{c|}{$\begin{array}{c}\text { Random coefficient } \\
\text { model }\end{array}$} \\
\hline -2*log likelihood & 7254.4834 & 6802.2541 & 6802.544 \\
\hline $\begin{array}{l}\text { Deviance based chi-square } \\
\text { test }\end{array}$ & 84.1252 & 245.213 & 0.6099 \\
\hline P-value & $0.0000^{*}$ & $0.0000^{*}$ & 6972.0152 \\
\hline \multicolumn{4}{|c|}{ Model Fit Diagnostics } \\
\hline AIC & 7295.012 & 6950.034 & 7096.182 \\
\hline BIC & 7312.187 & 7015.312 & \\
\hline
\end{tabular}

*significant at 5\% level

Table4: Results for Multilevel Logistic Regression Model without Explanatory Variables 


\begin{tabular}{|l|c|c|c|c|}
\hline Fixed part & Coefficients & S.E. & t-value & P-value \\
\hline & -1.18546 & 0.019 & -62.4 & $0.000^{* *}$ \\
\hline Random part & Estimate & S.E. & Z-value & P-value \\
\hline & 0.140688 & 0.0235 & 5.987 & $0.011^{*}$ \\
\hline Rho $(\rho)$ & 0.048546 & 0.0204 & 2.38 & $0.025^{*}$ \\
\hline $\begin{array}{l}\text { Deviance= 15,243.52, } \\
\text { Deviance-based Chi-square }=\mathbf{5 2 1 . 1 9}\end{array}$ & AIC = 15,247.52, $=\mathbf{1 5 , 2 4 8 . 3 1 ,}$ \\
\hline
\end{tabular}

**significant at $1 \%$ level, $\quad$ *significant at $5 \%$ level

Table 5: Results of Random Intercept and Fixed Coefficient Logistic Regression Model 


\begin{tabular}{|c|c|c|c|c|}
\hline \multicolumn{5}{|l|}{ Fixed part } \\
\hline Fixed effect & & S.E. & $\overline{\text { Z-Value }}$ & p-value \\
\hline \multicolumn{5}{|c|}{ Breast feeding status (Never breasted=ref.cat) } \\
\hline Ever breasted, not currently & -.6010689 & .2131114 & -2.82 & $0.005^{*}$ \\
\hline Still breast feeding & -.4555433 & .2165306 & -2.10 & $0.035 *$ \\
\hline \multicolumn{5}{|l|}{ Sex of child (female $=$ ref.cat) } \\
\hline Male & 0.7458415 & 0.14482 & 5.15 & $0.002^{*}$ \\
\hline \multicolumn{5}{|c|}{ Age of child (less than or equals to 29 months $=$ ref.cat) } \\
\hline Greater than 29 months & 0.2452757 & 0.0639085 & 3.84 & $0.000^{*}$ \\
\hline \multicolumn{5}{|c|}{ Residence of child (urban =ref.cat) } \\
\hline Rural & 0.2021277 & 0.0778864 & 2.60 & $0.009^{*}$ \\
\hline \multicolumn{5}{|c|}{ Level of education of Mother (no education =ref.cat) } \\
\hline primary & 0.4378549 & 0.080129 & 5.46 & $0.000^{*}$ \\
\hline secondary & 0.5244647 & 0.045434 & 11.54 & $0.004^{*}$ \\
\hline Higher & 0.6000154 & 0.064524 & 9.30 & $0.001^{*}$ \\
\hline \multicolumn{5}{|l|}{ Use of toilet (unsafe =ref.cat) } \\
\hline Safe & 0.400427 & 0.0910844 & 4.40 & $0.000^{*}$ \\
\hline \multicolumn{5}{|l|}{ Pregnant status (no =ref.cat) } \\
\hline Yes & 0.345115 & 0.0542164 & 6.37 & $0.005^{*}$ \\
\hline \multicolumn{5}{|c|}{ Food nutrient status (no =ref.cat) } \\
\hline Yes & 0.822101 & 0.061005 & 13.48 & $0.003^{*}$ \\
\hline Constant & -.8856897 & .2500704 & -3.54 & $0.000^{*}$ \\
\hline Random part & Estimate & S.E. & Z-value & P-value \\
\hline & 0.13432 & 0.06651 & 2.02 & $0.0217^{*}$ \\
\hline Intra-region correlation (rho) & .0392259 & .0178844 & 2.1933 & $\overline{0.0141^{*}}$ \\
\hline Deviance based chi-square & & 928.61 & & $0.000^{*}$ \\
\hline Deviance $=14,314.91$ & AIC & $14,751.85$ & $\overline{B I C}$ & $=14,762.01$ \\
\hline
\end{tabular}

*significant at $5 \%$ level, $($ ref $)=$ reference category, ICC: Intra-region correlation

Table 6: Results of Random Coefficient Multilevel Logistic Regression Model 


\begin{tabular}{|c|c|c|c|c|c|c|c|c|c|}
\hline \multicolumn{7}{|c|}{ Solutions for Fixed Effects } & \multicolumn{3}{|c|}{ Odds Ratio Estimates } \\
\hline \multirow[t]{2}{*}{ Effect } & \multirow[t]{2}{*}{ Level } & \multirow[t]{2}{*}{ Estimate } & \multirow[t]{2}{*}{$\overline{S . E}$} & \multirow[t]{2}{*}{$\overline{\mathrm{DF}}$} & \multirow[t]{2}{*}{$\begin{array}{l}\text { t- } \\
\text { value }\end{array}$} & \multirow[t]{2}{*}{$\overline{\operatorname{Pr}>|t|}$} & \multirow[t]{2}{*}{ Estimate } & \multicolumn{2}{|c|}{$\begin{array}{l}95 \% \\
\text { Confidence } \\
\text { Limits }\end{array}$} \\
\hline & & & & & & & & LCL & UCL \\
\hline Intercept & & -1.4765 & 0.3124 & 58 & -4.73 & $<.0001 *$ & . & . & . \\
\hline \multirow[t]{2}{*}{$\begin{array}{l}\text { Age of } \\
\text { child }\end{array}$} & $\begin{array}{l}>29 \\
\text { months }\end{array}$ & 0 & 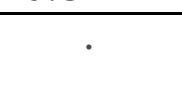 & - & - & - & . & · & . \\
\hline & \begin{tabular}{|l|}
$<30$ \\
months
\end{tabular} & 0.3513 & 0.1396 & 2797 & 2.52 & $0.0119 *$ & 0.219 & 0.164 & 0.293 \\
\hline \multirow{3}{*}{$\begin{array}{l}\text { Breast } \\
\text { feeding } \\
\text { status }\end{array}$} & $\begin{array}{l}\text { Never } \\
\text { breasted }\end{array}$ & 0 & • & • & • & - & . & • & - \\
\hline & $\begin{array}{l}\text { Ever } \\
\text { breasted } \\
\text { not } \\
\text { currently }\end{array}$ & -0.0124 & 0.1282 & 2797 & -0.10 & 0.9227 & 0.222 & 0.164 & 0.300 \\
\hline & \begin{tabular}{|l|} 
Still \\
breast \\
feeding
\end{tabular} & 0.5095 & 0.1053 & 2797 & 4.84 & $<.0001 *$ & 0.601 & 0.489 & 0.739 \\
\hline \multirow[t]{2}{*}{ Sex } & Female & 0 & & & & & & & \\
\hline & \begin{tabular}{|l|} 
Male \\
\end{tabular} & -0.4514 & 0.1722 & 2797 & -2.62 & $0.0088^{*}$ & 1.388 & 0.283 & 0.533 \\
\hline \multirow{2}{*}{$\begin{array}{l}\text { Residence } \\
\text { of child }\end{array}$} & Urban & 0 & & & & & & & \\
\hline & \begin{tabular}{|l|} 
Rural \\
\end{tabular} & 0.4356 & 0.1277 & 2797 & 3.41 & 0.0007* & 0.647 & 0.504 & 0.831 \\
\hline \multirow{4}{*}{$\begin{array}{l}\text { Level of } \\
\text { education } \\
\text { of } \\
\text { Mother }\end{array}$} & $\begin{array}{l}\text { no } \\
\text { education }\end{array}$ & 0 & • & - & . & • & . & $\cdot$ & . \\
\hline & \begin{tabular}{|l|} 
Primary \\
\end{tabular} & 0.01740 & 0.00668 & 2797 & 2.61 & 0.7451 & 1.033 & 1.004 & 1.031 \\
\hline & Secondary & 0.4950 & 0.1769 & 2797 & 2.80 & 0.2721 & 1.117 & 0.431 & 0.862 \\
\hline & \begin{tabular}{|l|} 
Higher \\
\end{tabular} & 0.7325 & 0.1449 & 2797 & 5.06 & 0.0862 & 1.223 & 0.984 & 1.634 \\
\hline \multirow{2}{*}{$\begin{array}{l}\text { Use of } \\
\text { toilet }\end{array}$} & Unsafe & 0 & & & & & . & . & \\
\hline & Safe & -2.3357 & 1.6853 & 2797 & -1.39 & 0.1659 & 0.097 & 0.004 & 2.635 \\
\hline \multirow{2}{*}{$\begin{array}{l}\text { Pregnant } \\
\text { status }\end{array}$} & No & 0 & & & & & & & \\
\hline & Yes & 1.4249 & 0.5159 & 2797 & 2.76 & $0.0058 *$ & 4.157 & 1.512 & 11.433 \\
\hline \multirow{2}{*}{$\begin{array}{l}\text { Food } \\
\text { nutrient } \\
\text { status }\end{array}$} & Yes & 0 & . & - & - & . & - & - & · \\
\hline & No & -0.45 & 0.17 & 28 & 4.06 & $0.0006^{*}$ & 1.239 & 0.28 & 0.53 \\
\hline \multicolumn{2}{|c|}{ Random effect } & B & S.E & \multicolumn{2}{|c|}{ Z-value } & \multicolumn{2}{|l|}{ P-Value } & & \\
\hline \multicolumn{2}{|c|}{$\operatorname{Var}\left(\mathrm{u}_{0 \mathrm{j}}\right)=\sigma^{2}{ }_{0}$} & & 0.070 & \multicolumn{2}{|c|}{2.12} & \multicolumn{2}{|c|}{0.0255} & & \\
\hline \multicolumn{2}{|c|}{$\operatorname{Var}\left(u_{2 j}\right)=\sigma^{2}{ }_{2}$} & 0.004 & 0.002 & \multicolumn{2}{|c|}{2.42} & \multicolumn{2}{|c|}{0.0041} & & \\
\hline \multicolumn{2}{|c|}{$\operatorname{Cov}\left(\mathrm{u}_{0 \mathrm{j}}, \mathrm{u}_{2 \mathrm{j}}\right)$} & -0.001 & 0.004 & \multicolumn{2}{|c|}{-2.34} & 0.0 & 039 & & \\
\hline $\begin{array}{l}\text { Deviance = } \\
14731.35, \\
\text { Deviance b }\end{array}$ & $\begin{array}{l}\text { 14281.85, } \\
\text { sed chi-squ }\end{array}$ & $=2$ & AIC & $=1472$ & 0.79 , & & $\mathrm{IC}=$ & & \\
\hline
\end{tabular}

\section{Figures}



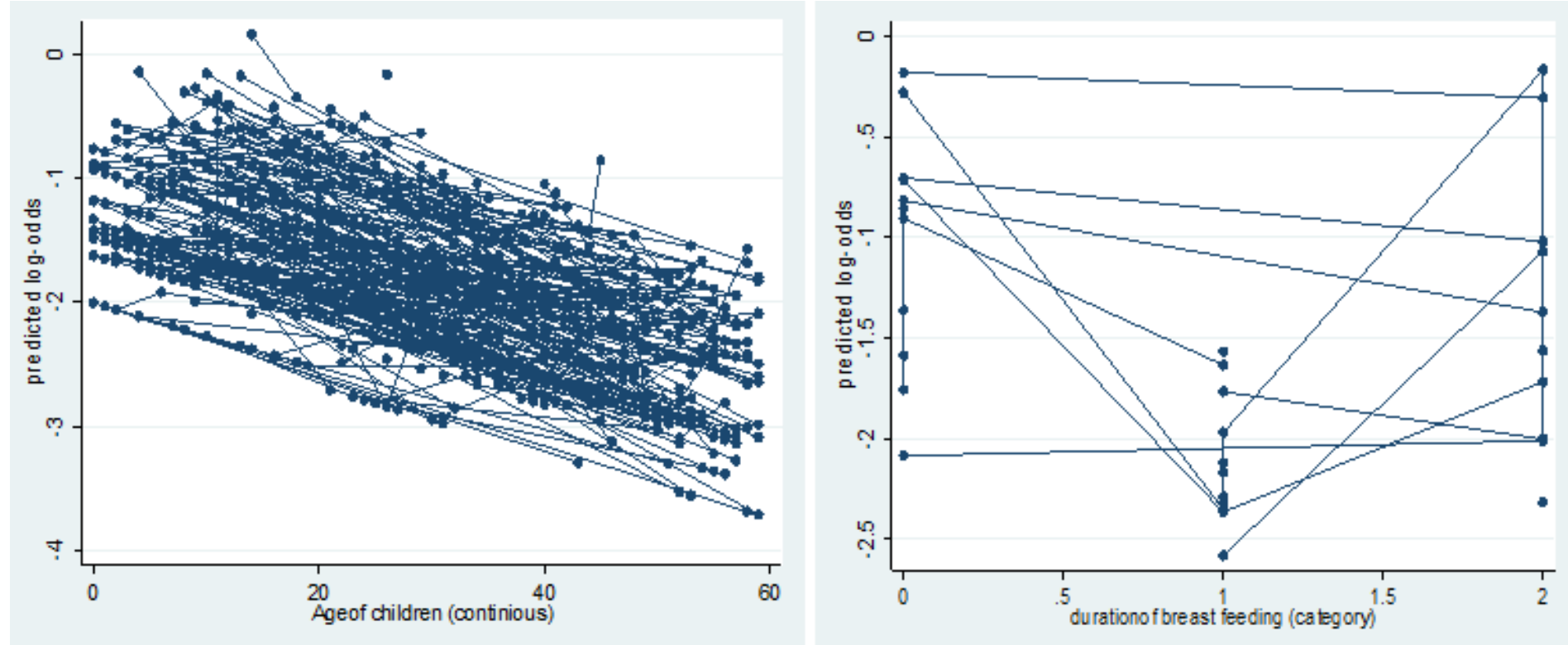

Figure 1

Predicted Probability of child stunting by child age and duration of breastfed vs Region

\section{Supplementary Files}

This is a list of supplementary files associated with this preprint. Click to download.

- Methods.pdf

- Methods.pdf 